\title{
The Effect of Hypoxia on Neurohypophyseal Hormone Release in Fetal and Maternal Sheep
}

\author{
HENDRIK STEGNER, (27) ROSEMARY D. LEAKE,(28) SUE M. PALMER, GARY OAKES, AND \\ DELBERT A. FISHER \\ Departments of Pediatrics and Obstetrics, UCLA School of Medicine, Harbor/UCLA Medical Center, \\ Torrance, California, USA
}

\begin{abstract}
Summary
The effect of hypoxemia on arginine vasopressin (AVP) and oxytocin (OT) release was investigated in the chronically catheterized fetus and ewe. During $30 \mathrm{~min}$ of $\mathbf{1 0} \%$ maternal oxygen delivery, mean $( \pm \mathrm{SEM})$ arterial $\mathrm{PO}_{2}$ decreased from $105 \pm 10.6$ to $48 \pm 3.5 \mathrm{~mm} \mathrm{Hg}$ in the ewe and from $21 \pm 1.3$ to $12 \pm 0.8$ $\mathrm{mm} \mathrm{Hg}$ in the fetus (each $P<0.001$ ). Arterial $\mathrm{PCO}_{2}$ decreased from $35 \pm 4.4$ to $29 \pm 1.0 \mathrm{~mm} \mathrm{Hg}$ in the ewe, whereas fetal $\mathrm{PCO}_{2}$ decreased from $43 \pm 2.3$ to $35 \pm 3.5 \mathrm{~mm} \mathrm{Hg}(P<0.05)$. Blood pH increased from $7.44 \pm 0.03$ to $7.56 \pm 0.04$ in the ewe $(P<$ $0.01)$ and from $7.36 \pm 0.004$ to $7.40 \pm 0.006$ in the fetuses $(P<$ 0.01 ).

Baseline mean AVP levels were identical in ewes and fetuses $(0.7 \pm 0.1 \mu \mathrm{U} / \mathrm{ml})$. After $30 \mathrm{~min}$ of hypoxia, plasma AVP levels remained unchanged in the ewes $(0.9 \pm 0.1)$, but increased dramatically in the fetuses $(47 \pm 21 \mu \mathrm{U} / \mathrm{ml})(P<0.001)$. There was a highly significant correlation between the duration of hypoxia and $\log$ fetal AVP concentrations $(r=0.85)$. The $\log$ fetal plasma AVP also was inversely correlated to the log fetal $\mathrm{PO}_{2}$ values $(r=0.83)$.

Mean baseline fetal and maternal plasma OT levels were 2.6 $\pm 0.5 \mu \mathrm{U} / \mathrm{ml}$ and $2.2 \pm 0.5 \mu \mathrm{U} / \mathrm{ml}$, respectively. After $30 \mathrm{~min}$ of hypoxia fetal and maternal OT values were $2.9 \pm 0.8 \mu \mathrm{U} / \mathrm{ml}$ (not significant).
\end{abstract}

\section{Abbreviations}

AVP, arginine vasopressin

OT, oxytocin

AVP and OT contents of the fetal pituitary and hypothalamus increase during gestation $(18,21)$. Fetal plasma AVP and OT levels are low during the last third of gestation and although the placenta is impermeable to AVP and probably OT, basal maternal and fetal blood concentrations of AVP and OT are similar $(7,12,22,23)$; however, it is clear that the ovine fetus is capable of responding to both osmotic and hypovolemic stimuli with AVP release early in the third trimester. After delivery, cord blood plasma AVP levels in newborn sheep and human infant are increased, more so after vaginal delivery than after Cesarian section delivery $(1,2,3,9,10,14,15)$. This AVP elevation has been attributed to cerebral compression $(6,9)$ or stress and hypoxia $(4,5,16)$.

Several studies using bioassay as well as radioimmunoassay methods for measuring AVP have shown that hypoxia is a potent stimulus for fetal AVP release $(1,17,25)$. These studies often combined hypoxia with hypercarbia however, and none measured the OT response.

In fact, little is known concerning OT responsiveness in the fetus. We and others have shown that cord blood plasma OT levels are elevated $(2,13)$, and there has been speculation that this elevation also may be due to hypoxia associated with delivery. The present study was undertaken to investigate the magnitude and timing of the AVP and OT responses to hypoxia, the latter as a single stimulus unassociated with hypercapnia and/or asphyxia.

\section{MATERIALS AND METHODS}

Animal preparation. Ketamine was administered to four datebred ewes (Columbia-Suffolk), three with singleton fetuses and one with twin fetuses. The fetuses were 125-129 d gestational age. Hysterotomy was performed, the fetal leg was exteriorized, and a catheter was inserted into the fetal dorsal vein and artery and advanced to the inferior vena cava and dorsal aorta. The fetal leg was then replaced in the uterus, the fetal catheters were exteriorized to a pouch attached to the flank of the ewe, the uterine incision was sutured and maternal abdominal wall was closed. Femoral venous and arterial catheters were inserted into the ewe. Catheters were maintained patent with a dilute heparin solution (1 U/4 ml blood).

Chloramphenicol was given to the ewe $(250 \mathrm{mg})$ and the fetus $(25 \mathrm{mg})$, and instilled into amniotic fluid $(250 \mathrm{mg})$ twice a day for five $d$ postoperatively. Animals were maintained in indoor pens and received feedings of baled alfalfa and water ad libitum. Five d were allowed for recovery from surgery.

Study protocol. On the day of study, water was removed from the cage. A fetal blood sample was obtained and the study was undertaken only if the fetal pH exceeded 7.3. Thirty milliliters whole blood was removed from the maternal circulation into a heparinized syringe ( $1 \mathrm{U}$ for $4 \mathrm{ml}$ blood) for subsequent transfusions to the fetus.

After three $(5 \mathrm{ml}$ ) baseline blood samples were obtained at 10 min intervals from the maternal femoral and fetal dorsal arterial lines for measurement of plasma AVP, OT, blood gases, and $\mathrm{pH}$, the ewe breathed a gas mixture containing $10 \%$ oxygen and $90 \%$ nitrogen for $30 \mathrm{~min}$. The gases were delivered to a bag placed over the ewe's head. A rapid flow rate was maintained so that $\mathrm{CO}_{2}$ accumulation did not occur. Oxygen content of the inspired gases was monitored continuously using a Beckman oxygen analyzer calibrated to room air and $100 \% \mathrm{O}_{2}$. Three $(5 \mathrm{ml})$ blood samples were obtained from the fetus and mother at 10,20 , and $30 \mathrm{~min}$ of $10 \% \mathrm{O}_{2}$ exposure. All samples were collected after twice the equivalent of the $1.5 \mathrm{ml}$ dead space of the catheters was withdrawn. Fetal blood withdrawn was replaced immediately with an equal amount of maternal blood.

One milliliter of each blood sample was placed in an iced heparinized tuberculin syringe for immediate blood gas and $\mathrm{pH}$ measurements. Four milliliters of each blood sample was collected in iced tubes prepared with $15 \%$ EDTA, and spun at 2000 
$\mathrm{r} / \mathrm{min}$ in a refrigerated centrifuge. Plasma was separated within $1 \mathrm{~h}$ and divided into two $1-\mathrm{ml}$ aliquots for storage at $-20^{\circ} \mathrm{C}$ until measurement of AVP as described previously $(20,26)$. One milliliter of plasma was immediately extracted for OT by the addition of two volumes of spectral grade acetone; samples then were centrifuged at $2000 \mathrm{r} / \mathrm{min}$ for $20 \mathrm{~min}$. The supernatant was decanted into the sample. An upper layer was allowed to form and the lower layer was aspirated into a $12 \times 75-\mathrm{mm}$ glass tube. The infranatant was then dried in a Savant condensor and stored at $-20^{\circ} \mathrm{C}$ until radioimmunoassay. Details of the radioimmunoassay have been published previously $(7,26)$. Sensitivity of the AVP assay is $0.15 \mu \mathrm{U} / \mathrm{ml}$, sensitivity of the OT assay, $0.45 \mu \mathrm{U} /$ $\mathrm{ml}$. Cross reactivities of arginine vasopressin, vasotocin, and mesotocin in the OT radioimmunoassay are $0.1 \%, 0.2 \%$, and $0.7 \%$, respectively. The OT radioimmunoassay within assay coefficient of variation is $6.7 \%$. Mean ( \pm SEM) OT extraction recovery was $72 \pm 3 \%$.

Means and standard errors of the mean values were calculated for all data. Mean values for baseline and posthypoxia data as well as comparisons between fetal and maternal values were both determined by two-way analysis of variance. Correlation coefficients were calculated by linear regression analysis. All data are recorded as mean \pm SEM.

\section{RESULTS}

During the 30 -min period of breathing $10 \% \mathrm{O}_{2}$, the maternal $\mathrm{PO}_{2}$ decreased from a baseline of $105 \pm 10.6$ (mean \pm SEM) to $48 \pm 3.5 \mathrm{~mm} \mathrm{Hg}(P<0.001)$ whereas fetal $\mathrm{PO}_{2}$ decreased from $21 \pm 1.3$ to $12 \pm 0.8 \mathrm{~mm} \mathrm{Hg}(P<0.001)$. Maternal $\mathrm{PCO}_{2}$ decreased from $35 \pm 4.4$ to $29 \pm 1.0 \mathrm{~mm} \mathrm{Hg}(P<0.05)$ due to hyperventilation whereas fetal $\mathrm{PCO}_{2}$ values decreased from $43 \pm$ 2.3 to $35 \pm 3.5 \mathrm{~mm} \mathrm{Hg}(P<0.05)$. Blood $\mathrm{pH}$ increased in the ewes from $7.44 \pm 0.03$ to $7.56 \pm 0.04$ and in the fetuses from $7.36 \pm 0.004$ to $7.40 \pm 0.006(P<0.01)$ (Fig. 1$)$.

Baseline plasma AVP levels were $0.7 \pm 0.1 \mu \mathrm{U} / \mathrm{ml}$ in the ewes and $0.7 \pm 0.1 \mu \mathrm{U} / \mathrm{ml}$ in their fetuses (not significant). After 30 min of $10 \%$ oxygen delivery to the ewes, the mean maternal plasma AVP level $(0.9 \pm 0.1 \mu \mathrm{U} / \mathrm{ml})$ was similar to the pre-study value. Fetal plasma AVP levels varied from 11-101 $\mu \mathrm{U} / \mathrm{ml}$ (mean, $47 \pm 21 \mu \mathrm{U} / \mathrm{ml} ; P<0.001$ ). Figure 2 shows the fetal and maternal plasma AVP concentrations before and during the hypoxic period. There was a highly significant correlation between the rise in log fetal AVP concentrations and duration of hypoxia (correlation coefficient, $r=0.85$ ). Figure 3 shows a significant positive correlation between decreasing levels of $(\log )$ fetal $\mathrm{PO}_{2}$ and $(\log )$ fetal plasma AVP values $(r=0.83)$.

Baseline fetal and maternal plasma OT levels were $2.6 \pm 0.5$ and $2.2 \pm 0.5 \mu \mathrm{U} / \mathrm{ml}$, respectively (not significant). After $30 \mathrm{~min}$ of breathing $10 \% \mathrm{O}_{2}$, fetal and maternal plasma OT levels were $2.9 \pm 0.8$ and $2.0 \pm 0.7 \mu \mathrm{U} / \mathrm{ml}$, respectively.

\section{DISCUSSION}

Our study presents the first plasma OT measurements during fetal hypoxia. Our fetal animals had a vigorous plasma AVP response to hypoxia given as a single stimulus, but they manifest no plasma OT response. We have shown previously that increases in both plasma AVP and OT occur in response to hemorrhage or hypertonic saline infusion in adult dogs (26). Furthermore, increases in both AVP and OT levels have been described in cord blood by several investigators $(2,3,9,10,13,14,15)$. The present results suggest that elevated cord blood OT levels are not due to fetal hypoxia. The precise stimulus remains to be clarified.

The timing of the elevations in cord blood AVP and OT levels $(2,3,9,10,13,14,15)$ relative to labor and delivery is unclear, but the increase may occur before parturition (1). Stark et al. (22) measuring plasma AVP levels during adrenocorticotropininduced labor in chronically catheterized fetal-maternal sheep preparations, found a significant increase during labor. This

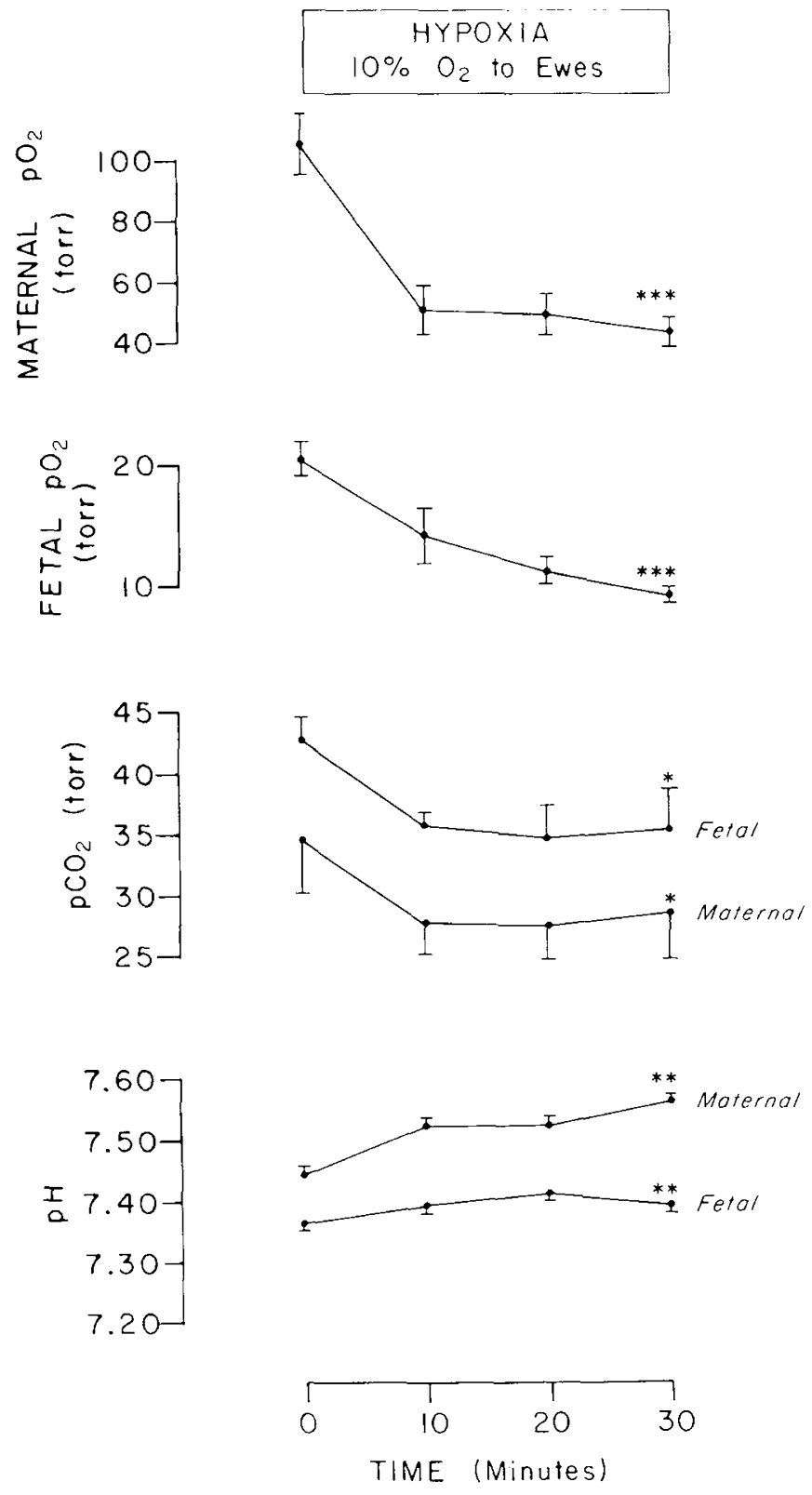

Fig. 1. Blood gas and $\mathrm{pH}$ values (mean $\pm \mathrm{SEM}$ ) in maternal and fetal plasma during $30 \mathrm{~min}$ of $10 \%$ oxygen delivery to the ewe.

increase seemed to be inversely correlated to the level of fetal oxygenation. Other investigators $(3,9,10)$ have reported a correlation between duration of labor and plasma AVP levels.

The mechanism responsible for AVP hypersecretion during delivery also is unclear. AVP concentrations in cord blood of infants delivered by Caesarian section usually are lower than values in infants born vaginally (19). One mechanism for fetal AVP release during labor and delivery might therefore be increased intracranial pressure (19), because in monkeys with chronically implanted intracerebral balloons, balloon inflation increases plasma AVP concentrations (6). Polin et al. (15) could not correlate increased plasma AVP levels after vaginal delivery with stress, cord blood $\mathrm{pH}$, or 1-min Apgar scores, however.

Examining the role of hypoxia as a stimulus for AVP secretion, Rurak (17) found an increase in plasma AVP levels in fetuses of hypoxic ewes and observed that this increase was correlated with a fall in fetal blood $\mathrm{pH}$. Our results do not confirm this correlation. Additionally, maternal plasma AVP levels did not increase in the study of Rurak or in the present study; however, the 


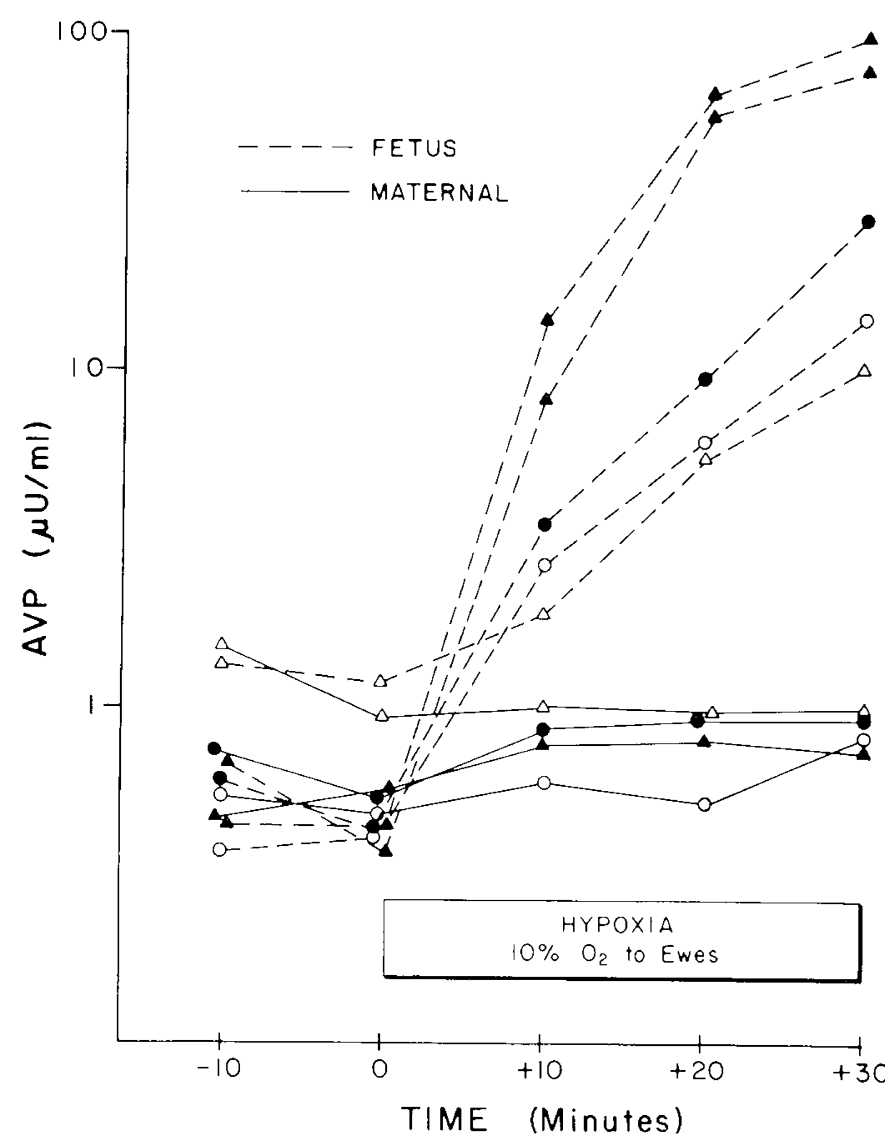

Fig. 2. Fetal and maternal plasma AVP levels during $10 \%$ oxygen breathing in four ewes and five fetuses.

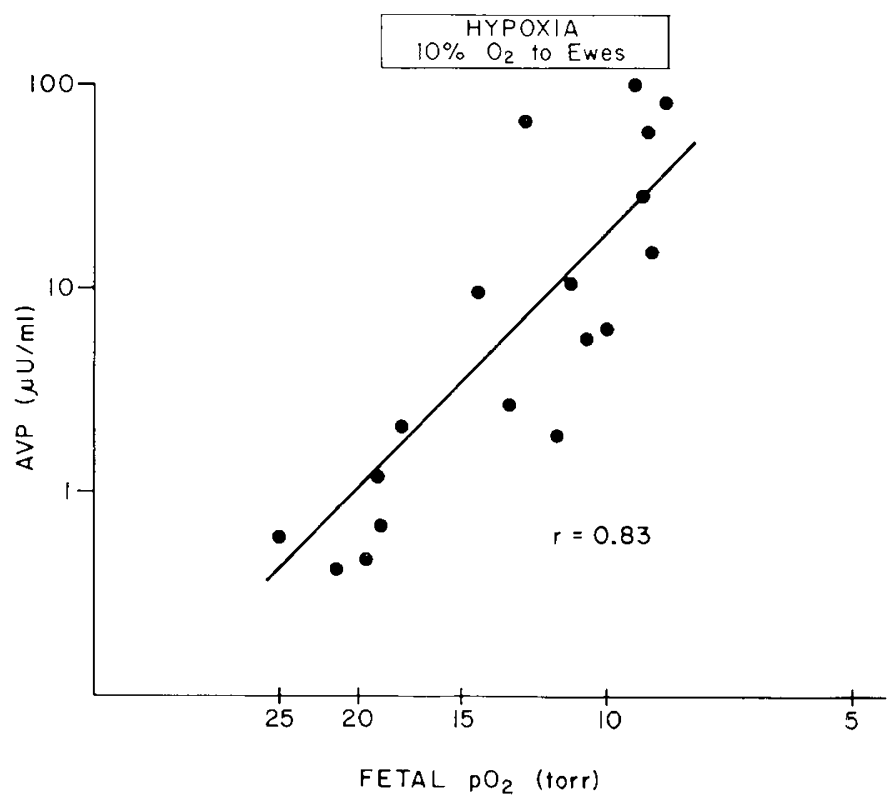

Fig. 3. Fetal plasma $\mathrm{AVP}$ and $\mathrm{PO}_{2}$ values during $10 \%$ oxygen delivery to the ewe. Data are plotted on double logarithmic scales $(r=0.83)$.

sensitivity in the AVP bioassay employed by Rurak was $5.0 \mu \mathrm{U} /$ $\mathrm{ml}$.

In a more recent study, Stark el al. (24) reported peak fetal plasma AVP values similar to ours after a 30 -min period of $10 \%$ oxygen delivery to the ewe. The blood sampling schedule, however, failed to show the exponential increase in fetal plasma AVP levels which our data demonstrate. In addition these authors reported a significant positive correlation between decreasing levels of fetal $\mathrm{PO}_{2}$ and the logarithm of the fetal plasma AVP increment $(r=0.75)$. In our study a better correlation coefficient was observed using a logarithmic scale for both plasma AVP and $\mathrm{PO}_{2}(r=0.832$, Fig. 3). In similar studies DeVane and colleagues (25) also studied fetal plasma AVP responses to maternal hypoxia in sheep, but the fetal AVP responses in that study were less than in the present report.

To study the mechanism of the AVP response to hypoxia, Rurak (17) severed the cervical vagosympathetic trunks in sheep fetuses and observed a somewhat reduced but intact increase in plasma AVP levels in response to hypoxia. In contrast, Share and Levy (19) demonstrated a role of carotid artery chemoreceptors in mediating the AVP response to hypoxia in adult dogs. This may represent species difference or differences between fetal and adult responses.

The observation in the present study that plasma AVP levels correlated with the duration of hypoxia suggests that hypoxia is a continuing stimulus to AVP secretion at least over a $30-\mathrm{min}$ period. In addition this correlation is compatible with a progressive increase in AVP secretion with continuing duration of hypoxia and/or a decreased rate of AVP degradation in the hypoxia state. We did not study AVP degradation in the hypoxic animals.

\section{REFERENCES AND NOTES}

1. Alexander, D. P., Bashore, R. A., Britton, H. G., and Forsling, M. L.: Maternal and foetal arginine vasopressin in the chronically catheterized sheep. Biol. Neonate, 25:242 (1974).

2. Chard. T.. Hudson, C. N.. Edwards. C. R. W.. and Boyd. N. R. H.: Release of oxytocin and vasopressin by the human foetus during labor. Nature, 234 $352(1971)$.

3. Czernichow, P. and Pattin, M.: La vasopressin chez le nouvcan-ne'; taux plasmatiques dans le sang du cordon et chez le mere. Ann. Endocrinol. (Paris) 39: 225 (1978).

4. Forsling. M. L. and Milledge. J. S.: Effect of hypoxia on vasopressin release in man. J. Physiol. (London), 267: 22P (1977).

5. Forsling. M. L. and Ullman, E. A.: Non-osmotic factors in vasopressin release In: A. M. Moses. L. Share: Neurohypophysis. (Kargar, Basel, 1977).

6. Gaufin. L. Skowsky. W. R., and Goodman. S. J.: Release of antidiuretic hormone during mass-induced elevations of intracranial pressure. J. Ncurosurg. 46: 627 (1977).

7. Glatz, T. H., Weitzman, R. E.. Nathaniclsz, P. W., and Fisher. D. A.: Metabolic clearance rate and transplacental pasage of oxytocin in the pregnant ewe and fetus. Endocrinology, 106: 1006 (1980).

8. Hackett, P., Forsling, M. L., Milledge, J., and Reanic, D.: Release of vasopresin in man at altitude. Horm. Mctab. Res., 10:571 (1978).

9. Hadeed. A. J.. Leake, R. D.. Weitzman, R. E., and Fisher. D. A.: Possible mechanisms of high blood levels of vasopressin during the neonatal period. J. Pediatr., 94: 805 (1979).

10. Hoppenstcin, J. M., Miltenberger, F. W., and Moran, W. H. Jr.: The increase in blood levels of vasopressin in infants during birth and surgical procedures. Surg. Gynecol. Obstet., 127:966 (1968).

11. Khane, S. K.: Neurohypophyseal dysfunction following perinatal asphyxia. J. Pediatr., 90:628 (1977).

12. Leake, R. D., Weitzman, R. E., Effros, R. M.. Siegel, S. R., and Fisher, D. A. Maternal fetal osmolar homeostasis: fetal posterior pituitary autonomy. Pediatr. Res., 13:84 (1979).

13. Leake, R. D., Weitzman, R. E., and Fisher, D. A.: Oxytocin concentrations during the neonatal period. Biol. Neonate, 39: 157 (1981).

14. Leung. A. K. C. McArthur. R. G.. McMillan. D. D.. Ko, D., Deacon. J. S. R. Parboosingh. J. T., and Lederis, K. P.: Circulating antidiuretic hormono during labor and in the newborn. Acta Paediatr. Scand., 69: 505 (1980).

15. Polin, R. A., Husain, M. K., James, L. S.. and Frantz. A. G.: High vasopressin concentrations in human umbilical cord blood-lack of corrclation with stress. J. Perinat. Med.. 5: 114 (1977).

16. Rudolph. A. M. and Iwamoto. H. S.: Neurohormonal regulation of the fetal circulation. In: Physiological and Biochemical Basis for Perinatal Medicine. Samuel Levine Conf. Ist Int. Med. Paris 1979, 263 (Karger, Basel, 1981).

17. Rurak. D. W.: Plasma vasopressin levels during hypoxemia and the cardiovascular effects of exogenous vasopressin in foetal and adult sheep. J. Physiol 277: 341 (1977).

18. Schubert, F., George, J. M., and Rao, B.: Vasopressin and oxytocin content of human fetal brain at different stages of gestation. Brain Res., 213: 11 (1981)

19. Share. L. and Levy. M.: Effect of carotid chemoreceptor stimulation on plasma antidiuretic hormone titer. Am. J. Physiol.. 210: 157 (1966).

20. Skowsky. W. R., Rosenbloom, A. A., and Fisher, D. A.: Radioimmunoassay of arginine vasopressin in serum development and application. J. Clin. Endocrinol. Metab.. 38: 278 (1974).

21. Skowsky. W. R. and Fisher. D. A.: Fetal neurohypophyseal arginine vasopressin 
and arginine vasotocin in man and sheep. Pediatr. Res.. 11: 627 (1977).

22. Stark. R., Husain, K., Daniel, S., Miliez, J., Morishima. H., and James, S. Characterization of vasopressin (AVP) release during adreno corticotrophin induced parturition in the lamb. Pediatr. Res., 11:412 (1977).

23. Stark, R. J., Daniel, S. S., Husain, K. M., James, L. S., and Vande Wicle, R. L.: Arginine vasopressin during gestation and parturition in sheep fetus. Biol. Neonate. 35: $235(1980)$.

24. Stark, R. J., Wardlow, J. L., Daniel, S. S., Husain, M. K., Sanocka, W. M. James, L. S., and Vande Wiele, R. L.: Vasopressin secretion induced by hypoxia in sheep: developmental changes and relationship to $\beta$-endorphin release. Am. J. Gynecol., 143: 204 (1982).

25. DeVanc, G. W., Nadan, R. P., Porter, J. C., and Rosenfeld, C. R.: Mechanism of arginine vasopressin release in the sheep fetus. Pediatr. Res. 16: 504 (1982).

26. Weitzman, R. E. Glatz, T. H., and Fisher, D. A.: The effect of hemorrhage and hypertonic saline upon plasma oxytocin and arginine vasopressin in conscious dogs. Endocrinology. 103: 2154 (1978).

27. Hendrik Stegner was supported by the Deutsche Forschungsgemeinschaft, West Germany.

28. Requests for reprints should be addressed to: Dr. Rosemary D. Leake, Dep of Pediatrics. Harbor/UCLA Medical Center, 1000 West Carson Street, Torrance, CA 90509

29. This research was supported in part by Grant \#HD06335 from the National Institute of Child Health and Human Development, Bethesda, Maryland.

\title{
Glucocorticoid-Thyroid Hormone Interactions in Fetal Rat Lung ${ }^{(13)}$
}

\author{
IAN GROSS ${ }^{(40)}$ DIANE W. DYNIA, CHRISTINE M. WILSON, LINDA D. INGLESON, \\ IRA H. GEWOLB, ${ }^{(39)}$ AND SEAMUS A. ROONEY \\ Division of Perinatal Medicine, Departments of Pediatrics and Obstetrics and Gynecologv Yale University School \\ of Medicine, New IIaven Connecticut, USA
}

\begin{abstract}
Summary
Previous studies have shown that triiodothyronine $\left(\mathrm{T}_{3}\right)$ enhances the effect of dexamethasone on phosphatidylcholine (PC) synthesis in organ cultures of fetal rat lung. The aim of this study was to investigate whether similar interactions occurred in vivo and to explore possible mechanisms for this phenomenon.

Injection of $7.0 \mathrm{mg} / \mathrm{kg} \mathrm{T}_{3}$ into pregnant rats on d 18 and 19 of gestation resulted in a mean fetal serum $T_{3}$ level of $2380 \mathrm{ng} / \mathrm{dl}$ on d 20 (control, $84 \mathrm{ng} / \mathrm{dl}$ ) and in maximal (34\%) stimulation of choline incorporation into PC. Injection of $1.0 \mathrm{mg} / \mathrm{kg}$ betamethasone using the same protocol as for $T_{3}$ resulted in maximal stimulation of $33 \%$ and administration of both hormones together produced a $69 \%$ increase, an additive affect. The percentage of PC that was disaturated was increased with betamethasone, but decreased with $T_{3}$. Betamethasone treatment resulted in an increase in the whole lung disaturated $\mathrm{PC}$ content, but treatment with $T_{3}$ did not. Betamethasone administration also increased fetal serum $T_{3}$ levels, but $T_{3}$ injection did not produce elevated fetal serum corticosterone levels.

Injection of $\mathrm{T}_{3}$ in vivo, or exposure of explants of 18-d fetal lung to $100 \mathrm{~nm} \mathrm{~T}_{3}$ for up to $48 \mathrm{~h}$ did not result in an increase in cytoplasmic glucocorticoid binding or nuclear translocation of the receptor steroid complex. Exposure of explants to glucocorticoid or $T_{3}$ in vivo or in culture (dexamethasone, $100 \mathrm{nM}$ and $T_{3}, 100$ $\mathrm{nM}$; for $48 \mathrm{~h}$ ) resulted in a significant increase in the activity of cholinephosphate cytidylyltransferase, an enzyme in the choline incorporation pathway of PC synthesis. Exposure of explants to the combination of hormones resulted in stimulation that was equal to the sum of that produced by the single hormones but was not statistically significantly different from the glucocorticoid effect. The activities of other enzymes of phospholipid synthesis were not increased by exposure to either hormone, in vivo or in vitro.
\end{abstract}

The additive effects of $T_{3}$ and glucocorticoid with regard to choline incorporation into $\mathrm{PC}$ in fetal rat lung suggest that combined hormone therapy may be useful for the prevention of respiratory distress syndrome in humans. Further animal studies are required, however, before clinical use can be considered.

\section{Abbreviations}

CDP, cytidine $5^{\prime}$ diphospho

DIMIT, 3,5-dimethyl-3'-isopropyl-L-thyronine

PC, phosphatidylcholine

RDS, respiratory distress syndrome

$T_{3}$, triiodothyronine

Interactions between glucocorticoids and thyroid hormones occur in a number of tissues (31). A previous study from this laboratory showed that there are additive interactions between dexamethasone and $\Upsilon_{3}$ with regard to phospholipid synthesis in explants of fetal rat lung in organ culture (11). Both dexamethasone and $T_{3}$ stimulated the rate of choline incorporation into $\mathrm{PC}$ in these cultures and the effect of the combination of these hormones was equal to or greater than the sum of their individual actions. Another of our previous studies indicated that glucocorticoids and thyroid hormones have different effects on fetal lung phospholipid metabolism, suggesting that these hormones act at different biochemical sites $(10)$.

The aim of this study was 2-fold. First, we wanted to determine whether the interactions observed in vitro would occur in vivo. The second goal was to determine whether the interactions occur at the level of cytoplasmic glucocorticoid receptor, nuclear translocation of the receptor-steroid complex, or at the translational level. To explore this, we examined the effects of $T_{3}$ on dexamethasone binding, in vivo and in vitro, and the effects of glucocorticoids, $\mathrm{T}_{3}$, and a combination of these two hormones on the activity of a number of enzymes of phospholipid synthesis.

\section{MATERIALS AND METHODS}

In vivo studies. In order to avoid problems associated with direct fetal injection, all hormones were injected into the mother. 